\title{
THE DISAPPEARANCE OF DARKNESS
}

\author{
NORMAN SPERLING \\ Chabot Observatory \\ Oakland, CA U.S.A.
}

\section{INTRODUCTION}

Until the last century, virtually all humans knew the appearance of the dark night sky. Even unschooled urbanites knew some constellations and planets. By 1909 , light pollution made authors admonish readers to do their skywatching from the countryside rather than the city. The warnings have escalated along with the light pollution. Light pollution's effect on professional and volunteer observational astronomy, along with telescopes' changing focal ratios, largely determine which kinds of astronomy are done in which institutions. In times and places where individuals perceive little possibility to change their culture, astronomers cope as best they can. When activism earns results in other cultural matters, astronomers sometimes become activists to fight light pollution. Chabot Observatory has felt many of these influences in its 105-year history, and they can be read in its plans for the future as well. Despite winning some battles, the war against light pollution is still being lost, so a different approach is suggested.

\section{FIRST-WORLD LIGHT POLLUTION}

Attention to light pollution depended, and still depends, upon local and cultural conditions. Geography, meteorology, energy consumption methods, economics, technology, politics, and demography all mold local circumstances, and generate objectionable levels of light pollution at different times in different places. Light pollution's interrelationships with popular astronomy, professional and amateur research, instrumentation, and observing sites demonstrate its strong influence.

Light pollution is high in the consciousness of those who suffer from it nightly, but writers used to dark skies rarely mention it. Writers in smoky cities bemoan smoke, and writers in electrically-lit cities bemoan electric lights--though writers in cloudy climates bemoan the clouds at least as loudly. So the writers talk about whatever interferes with their skywatching. And none ever hints that anything can be done to avoid it, except travel.

By 1866 , and perhaps earlier, the first caveats about light pollution crept into the popular astronomical literature. Sir John Herschel (1792-1871) noted the problem (Crawford, personal communication). Amedee Guillemin (1866) wrote that the dimmest stars are effaced altogether "in the great centers of population, by the illumination of the houses and streets." The haze enveloping 
Paris and London, and the smoke filling the skies of many cities, was the primary obstruction, however. It was largely wood and coal smoke plus street dust; we would call it air pollution. It still wasn't too bad, because in 1869, Edwin Dunkin was still able to advocate urban skywatching: "It is of no consequence, therefore, in what part of London, or its neighborhood, the observer is located. It may be in the heart of the city..." But another Londoner, John A. W. Oliver, wrote of the Zodiacal Light by 1888, that "the less luminous portions cannot be well seen in a town where there is smoke illuminated by gaslight, or where the electric light is in use, as in the city of Boston (U.S.A.), where Searle finds it no longer possible to observe the Zodiacal Light satisfactorily." Therefore, light pollution has definitely interfered with astronomical observing for appreciably more than 100 years.

From that time on, professional astronomers have almost always considered seeing conditions when locating new observatories. In addition to climate and altitude, they include light pollution as a prime consideration. While San Jose, Flagstaff and Pasadena were still small, dim towns, Lick, Lowell and Mount Wilson Observatories grew on nearby peaks -- only to suffer terribly in the light of recent developments.

Light pollution became a pressing topic in British and American -- and even Austrian -- popular astronomy books and amateurs' observing manuals from 1909 on. The problem escalated, both in the skies and in print, as the 1920s yielded to the 1930s, with authors preferring more and stronger warnings.

Then World War II blacked out major cities. All of a sudden, generations of urbanites who had never seen the starfilled sky clamored for books about this splendid vision, and despite wartime paper rationing, England (among other places) generated volumes to explain the sky. These old-fashioned star-watching manuals addressed readers who were seeing the dark sky as a novel phenomenon.

After the War, "the lights came on all over the world," the skies lit up again, urbanites lost touch with the stars, and books returned to their warnings to seek dark -- typically rural -- skies. Now, great numbers of city children attending planetarium shows cannot relate to the dark sky shown because they have never experienced such a sight in nature. Decisions made by generations unfamiliar with nature often seem to ignore it, with results ranging from regrettable to catastrophic.

And, now that most towns are light-polluters, observatories have been pushed farther away -- Fort Davis, Kitt Peak, Mauna Kea, Teneriffe, Las Campanas. A peak's isolation is now one of its prime astronomical assets, almost regardless of the difficulties imposed on construction and operation. Astronomers working on low-surface-brightness problems depend on such facilities. Observational astronomers working in light-polluted areas are restricted to high-surface-brightness topics, most of which are far from the forefront.

\section{FAST OPTICS ACCENT LIGIIT POLLUTION}

An often-overlooked element in the rising clamor has been the change in focal ratio of both professional and amateur telescopes. Most 19 th Century telescopes were $\mathrm{f} / 15$ to $\mathrm{f} / 20$ refractors. Such instruments excel for positional 
astronomy, as well as with high-surface-brightness objects like planets and double stars -- and are relatively unbothered by diffuse skyglow because they operate at high magnifications with small fields of view. That is why most remain in the cities and campuses where they were first set up, and why so few have been moved to remote mountaintops.

Since World War II, however, the overwhelming majority of professional and amateur observing has been accomplished with reflectors. It is relatively easy to make reflectors optically fast (a difficult problem for refractors), and preferable for cutting exposure time, and lowering the cost of mounting and housing. Fast optics concentrate diffuse light, so they excel for deep-sky observing of low-surface-brightness nebulae, clusters, and galaxies (Sperling, 1985).

With their large, fast reflectors, amateurs have waxed enthusiastic for deepsky observing. Several people have called this a result of the aperture explosion, which is perhaps spurred by economics as well as technology. But the faster focal ratios have been at least as much a factor as the wider apertures. And it is just those fast focal ratios that yield the wide fields of view and low magnifications that accent light pollution. Thus, when amateurs poured huge sums into huge telescopes to see huge distances, they found light pollution glaring back at them, preventing them from enjoying the view they had invested so much to see.

\section{POLITICAL ACTIVISM}

In the United States in the 1960s and 70s, light pollution increased precipitously with population, more brightly-lit cities, and suburban sprawl; amateur focal ratios sped up greatly, amateur apertures exploded enormously -and political activism spread from the Civil Rights movement to opposing the Viet Nam war and popular causes in general. This national mood gave American professional and amateur astronomers the idea to become activist -- actually fighting light pollution, instead of merely running away from it.

The struggle in the United States, Britain, and Canada is largely political. Mostly through amateur astronomy clubs, American and British hobbyists have repeatedly challenged offensive lighting, and have won several notable battles (itemized in Sperling, 1978, 1980, and 1986).

The first major salvo came from Tucson-area professional observatories in December 1971. Subtitled "A Guide for Businessmen and the General Public," it described the problem and the ordinance they proposed to cope with it (Steward, 1971). The ordinance passed, and Southern Arizona astronomers have been leaders in the struggle ever since. They continue issuing assorted publications (such as Crawford, 1985), monitor Arizona's slowed-but-still-growing light pollution, and undertake such other strategies as organizing IAU Colloquium 112 and the International Dark-Sky Association.

In 1973 and 1974, the United States endured a painful fuel shortage of political origin. Professional and amateur astronomers seized upon an anti-waste strategy for fighting light pollution, and the struggle took on its current aspect. Kurt Riegel published his survey paper in Science (Riegel, 1973), and Kitt Peak National Observatory issued another, more comprehensive book explaining the problem and recently-passed laws restricting the growth of outdoor lighting (Hoag and Peterson, 1974). 
In Manassas, Virginia, at the 18 May 1974 Middle East Regional convention of the Astronomical League, an unprecedented array of leading amateur astronomers passed and published a battle plan. It was authored by Jack Betz of Harrisburg, $\mathrm{Pa}$., and championed by the usually-reactionary Bob Wright, as well as several much more activist leaders, including myself. Betz advocated a succession of measures, from shielding the observing area, through contacting neighbors and utilities, to seeking governmental action (Betz, 1974). Several regions of the Astronomical League (the American Federation of Astronomy Clubs) have sponsored activist projects fighting light pollution since then, most notably the South East and Great Lakes regions. These efforts typically collect and distribute anti-light-pollution campaign literature, for use by local astronomy clubs. Of course, every amateur works on his own time with his own resources, so these efforts flare up and subside sporadically.

On 1 November 1974, the Toronto Centre of the Royal Astronomical Society of Canada's "Sky Brightness Programme" issued a manual telling how to measure light pollution photometrically. This was another salvo in amateur activism, taking a scientific-measurement stance (Berry, 1974). It has been pursued professionally by Arthur Upgren and others.

One of my articles (Sperling, 1980) pointed out that astronomers most often succeed when they exercise personal connections with government officials -- a very depressing conclusion for societies so proud of their democracy. This may result from a cultural climate in which the kinds of people who become public officials rarely know much science, and astronomy is so far from their awareness that they don't sufficiently understand an astronomer with an odd claim. They listen much more closely to individuals whose personal credibility they already know. Whatever the reason for this effect, astronomers would be wise to take advantage of personal acquaintances among government officials to fight light pollution.

Some local governments force dark-sky advocates to radical positions, as has happened in defense of Palomar Mountain Observatory near San Diego. There, John and Stephanie Mood write and speak from a radicalized stance, having learned that their local politicians respond to nothing less (Mood and Mood, 1985).

Politics also affect other aspects of the struggle. Sky and Telescope magazine frequently plants ideas with its readers. A major article fighting light pollution was delayed more than a year because of political considerations: an amateur astronomer who wrote it joined S\&T's rival, Astronomy magazine, and S\&T editors were exceedingly reluctant to publish his by-line (Pike and Berry 1978). This phobia delayed the American fight against light pollution.

Major differences remain between the professional and amateur astronomers' advocacies. Professional astronomers, who do lots of spectroscopy, emphasize narrow-spectrum lighting and early-morning turnoffs. Amateurs, whose work is usually broad-band in the evening, campaign for hooding lights.

\section{CHABOT OBSERVATORY}

Chabot Observatory's experience reflects these trends. Only a few gas lights lit Oakland, California, when Anthony Chabot gave the city its public 
observatory in 1883. Over the following three decades, however, its downtown site suffered increasingly from light pollution, so during World War I it was moved to a then-remote site in nearby hills -- quite dark, and isolated from houses, traffic, and industry (Morrison, et al., 1983).

Development since World War II has surrounded the site with houses, street lights, and freeways. Public policy has flooded Oakland's skies with waste lighting, particularly from the adjacent freeways, and also from the shipping Port. Since the early 1970's astronomers have been trying to move the observatory yet again, this time to the middle of a ridgetop park where lights can never encroach too near (Sperling 1984). The new site's advantages also include tree, ridge, and fog shielding from the bulk of city lights.

Local governments' internal politics have stymied the move for 15 years. Just now, however, they are approving a new charter making the observatory an independent public entity, with authority to rebuild at the new site. Major fund raising will start shortly after the new board begins operations. The new facility is expected to retain all the present major telescopes -- 3 of them long refractors -- with an enlarged and updated planetarium, library, computer and optical facilities, and much else. Planners hope to take maximum advantage of electronics, including computers, to facilitate public telescope use. The public will continue to be reminded that the light pollution they generate prevents them from seeing celestial objects optimally.

\section{THE DEVELOPING WORLD}

Much of the second and third world has yet to follow the path to development and pollution. Even now there are many places where light pollution is still minimal -- amateur observers I have visited in Arusha, Tanzania, and Faaa, Tahiti, are blissfully unaffected. The towns are small and concentrated, and use relatively low technology. They have no history of light pollution.

Elsewhere, different political systems impose different attitudes. I recently visited a very nice amateur club observatory in the capital city of a military dictatorship. Street lights glare almost all the way up to their doorstep. But they adamantly refuse to approach officials because "it is best if the government doesn't notice you at all." There, too, the solution is political rather than scientific, but necessitates terminating the dictatorship -- obviously a bigger problem than light pollution. I am greatly distressed to notice that many countries, in their rush to build American-style industry and infrastructure, seem determined to repeat, as well, every mistake we have made in our own development. Those countries should notice the fabulous price that America now pays to restore its environment, mostly to undo our previous mistakes. Among these mistakes are many which contribute to air and light pollution. I fervently urge other countries to learn from our mistakes and deliberately avoid them, on their ways to development. "Those who do not learn from history are condemned to repeat it." 


\section{A RECIPE TO CHANGE THE FUTURE}

Though this history of light pollution offers some inspiration, it also teaches that we are still losing, and losing badly. Present tactics win only limited, local victories, while light pollution increases, even where restricted by ordinances. Therefore, this history suggests that we must take other approaches.

Eliminating waste lighting will help all astronomers, and also the consumers who pay for lighting, while conserving resources used to generate the waste. Sometime, there will be another energy crunch, or economic setback, or major reverse in public approval of utilities. To be ready when that happens, our coalition should design a new type of luminaire to satisfy our own criteria along with the public's. I think these include:

$===$ no light above $15 \sim$ below horizontal

$==$ smooth spread of light over target area on ground

$===$ target area easily tailorable, perhaps by adjustable side shields

$===2$ or 3 narrow emission lines (perhaps from separate tubes phosphorescence, or other means) that the human eye will accept for decent color rendition, but at wavelengths not critical to spectroscopy, dim to color-film emulsions, and easy and cheap to filter

$===$ easy and cheap to manufacture

$==$ rights easy to license to everyone who will make them

$===$ economical to operate (easy installation and replacement, low power consumption, long life)

We should develop this luminaire. When we have it ready, we should promote it with all manufacturers, utilities, government authorities, and the public. When we offer a luminaire demonstrably superior for the public's purposes, it should win widespread acceptance, especially in an energy crunch. Since we also tailor it to suit our own purposes, that is how we can achieve our eventual victory.

\section{REFERENCES}

Baker, Robert H., "When the Stars Come Out", New York, Viking Press, revised edition, 1954, p.24.

Beet, Ernest Agar, "The Sky and Its Mysteries", London, G. Bell and Sons, 1957, p.11.

Bernhard, Hubert J., Dorothy A. Bennett, and Hugh S. Rice, editors, "Handbook of the Heavens", New York, Whittlesey House, 1935 (first edition), pp. 83-84.

Berry, Richard, "A Manual for the Study of Light Pollution", Toronto Center, Royal Astronomical Society of Canada, 1 November 1974.

Betz, Jack, "Dark Pollution", Middle East Region, Astronomical League, 18 May 1974.

Chant, Clarence Augustus, "Our Wonderful Universe", Yonkers-on-Hudson, NY, World Book Co., 1928(?), p. 150.

Crawford, David L., "Light Pollution: The Adverse Impact of Urban Sky Glow on Astronomy and on the Environment," Tucson, Arizona, National Optical Astronomy Observatories, Kitt Peak National Observatory, October 1985. 
Crawford, David L., personal communication, August 1988.

Draper, Arthur L, and Marian Lockwood, "The Story of Astronomy", New York, Dial Press, 1939, p.24.

Dunkin, Edwin, "The Midnight Sky: Familiar Notes on the Stars and Planets", London, The Religious Tract Society, 1869 (?), p.3.

Guillemin, Amedee, Le Ciel, 3d edition, Paris: L. Hachette, 1866. pp. 384-385. This is the earliest edition I have been able to check.

Guillemin, Amedee, edited by J. Norman Lockyer, revised by Richard A. Proctor, "The Heavens: An Illustrated Handbook", 4th English edition, New York: Scribner, Welford, 1871, pp. 271-273.

Hale, George Ellery, "The New Heavens", New York: Charles Scribner's Sons 1923, p.1.

Hinks, Arthur R., Astronomy, London: Oxford University Press, 1944 printing of 1936 second edition, p.11.

Hoag, Arthur A., and A. R. Peterson, "Observatories and Outdoor Lighting", Tucson, Kitt Peak National Observatory, April 1974.

Martin, Martha Evans, and Donald Howard Menzel, "The Friendly Stars", New York: Dover Publications, 1964 edition, p.82.

Mood, John and Stephanie, "Palomar and the Politics of Light Pollution", Astronomy Vol. 13, No. 11, November 1985, pp. 6-23.

Morrison, Martin E., Allen B. Takahashi, and Kingsley, W. Wightman, "Chabot's Century of Science Education", Sky \& Telescope, Vol. 65, No. 5, May 1983, pp. 398-400.

Neely, Henry M, "A Primer for Star-Gazers", New York, Harper and Brothers, 1946, (first edition), p.19.

Olcott, William Tyler and Edmund W. Putnam, "Field Book of the Skies", New York, G. P. Putnam's Sons, 1929 (first edition), p. 441.

Oliver, John A. Westwood, editor, "Astronomy for Amateurs", London: Longmans, Green, 1888, p.295.

Pike, Robert, and Richard Berry, "A Bright Future for the Night Sky", Sky \& Telescope, Vol. 55, No. 2, February 1978, pp.126-129.

Riegel, Kurt W., "Light Pollution", Science, Vol. 179, 30 March 1973, pp. 1285 1291.

Riegler, Gideon, "The Amateur Astronomer", London: T. Fisher Unwin, 1910, pp. 20-23.

Serviss, Garrett P., "Curiosities of the Sky", New York; Harper and Brothers 1909, p. 312.

Serviss, Garrett P., "Round the Year with the Stars", New York: Harper and Brothers 1910, p.17.

Sidgwick, J. B. "Introductory Astronomy: A Guide for Night Watchers", New York: Philosophical Library, 1944, p.v.

Smart, W. M., "The Sun, the Stars, and the Universe", London: Longmans, Green 1928, p.143.

Smith, Clarence R., "Earth and Sky: Marvels of Astronomy", Chicago: University of Knowledge, 1938, p.69.

Sperling, Norman, "How to Fight Light Pollution", Sky \& Telescope, Vol. 55, No. 2, February 1978, pp.133-138.

Sperling, Norman, "Licking Light Pollution", Sky \& Telescope, Vol. 60, No.1, July 1980 , pp. $17-20$.

Sperling, Norman, "100 Years at Chabot Observatory", Astronomy, Vol. 12, No. 
1, January 1984, pp. 26-28.

Sperling, Norman, "Of Pupils and Brightness", Griffith Observer, Vol. 49, No. 1, January 1985, pp.14-19.

Sperling, Norman, "Light Pollution: A Challenge for Astronomers", Mercury, Vol. 15, No. 5, September-October 1986, pp.144-150.

Stetson, Harlan True, "Man and the Stars", New York: Whittlesey House, 1930, p.5.

Steward, Kitt Peak National, and Smithsonian Astrophysical Observatories, "Light Pollution: A Threat to Astronomy in Pima and Santa Cruz Counties", Tucson, December 1971.

Swezey, Goodwin Deloss, and J. Harris Gable, Boys Book of Astronomy, New York: E.P. Dutton, 1921, p.63. 